\title{
Expression and Clinical Significance of Livin Protein in Hepatocellular Carcinoma
}

\author{
Hua Guo, ${ }^{1}$ Ying-tang Gao, ${ }^{1}$ Qin Zhang, ${ }^{2}$ Li Jing, ${ }^{1}$ Tong Liu, ${ }^{1}$ Wen-xia Shi, \\ Dao-kuan Zhai, ${ }^{1}$ Xiang Jing, ${ }^{3}$ and Zhi $\mathrm{Du}^{4}$ \\ ${ }^{1}$ Key Laboratory of Artificial Cell, Institute for Hepatobiliary Disease, Tianjin Third Central Hospital, Jintang Road 83, \\ Hedong District, Tianjin 300170, China \\ ${ }^{2}$ Department of Pathology, Tianjin Third Central Hospital, Tianjin 300170, China \\ ${ }^{3}$ Department of Radiology, Tianjin Third Central Hospital, Tianjin 300170, China \\ ${ }^{4}$ Department of Hepatobiliary Surgery, Tianjin Third Central Hospital, Tianjin 300170, China
}

Correspondence should be addressed to Ying-tang Gao; gaoyt816@163.com

Received 30 June 2013; Revised 12 September 2013; Accepted 16 September 2013

Academic Editor: Marco Peluso

Copyright (C) 2013 Hua Guo et al. This is an open access article distributed under the Creative Commons Attribution License, which permits unrestricted use, distribution, and reproduction in any medium, provided the original work is properly cited.

In this study, the two-step PV method of immunohistochemistry was used to determine livin protein expression in HCC tissues, pericarcinoma tissues, hepatitis/hepatic cirrhosis tissues, and normal hepatic tissues, and livin protein expression was detected in the blood plasma of patients with HCC before and after surgery, subjects with hepatic cirrhosis and hepatitis, and healthy blood donors using ELISA. Livin protein expression was significantly higher in HCC tissues than that in normal hepatic tissues and hepatitis/hepatic cirrhosis tissues, with no significant difference between HCC tissues and pericarcinoma tissues. The HCC patients with positive livin protein expression had a significantly higher survival rate than those with negative livin protein expression. Livin protein expression was significantly higher in the blood plasma of patients with HCC before and after surgery and in patients with hepatic cirrhosis and hepatitis than that in healthy blood donors, whereas livin protein expression in the blood plasma of patients with HCC was not significantly different from that of patients with hepatic cirrhosis and hepatitis. Livin protein expression in HCC tissues did not correlate with that in the blood plasma of the same HCC patients. Livin protein expression may be a potential, effective indicator for assessing prognosis in patients with HCC.

\section{Introduction}

Hepatocellular carcinoma (HCC) is a type of highly malignant cancer with insidious onset, fast progression, and a low 5 -year survival rate. Early diagnosis and precise evaluation of the prognosis are critical to improve the diagnosis and treatment of HCC. A search for specific biomarkers for the diagnosis and assessment of prognosis of HCC is therefore urgently needed. Serum alpha fetoprotein (AFP) has been the most widely used tumor marker for HCC for several decades. Nevertheless its sensitivity and specificity remain unsatisfactory, which easily causes missed diagnosis and misdiagnosis [1]. A search for tumor markers with higher sensitivity and specificity for detecting HCC has been given a high priority, so as to enhance the early diagnosis of HCC and thereby improve the quality of life of HCC patients.

The inhibitors of apoptosis proteins (IAPs) are a family of functionally and structurally related proteins, which are closely associated with tumor occurrence and development. The IAP family consists of 8 members, termed baculoviral IAP repeat containing (BIRC) 1-8. BRIC7, also known as livin, melanoma inhibitor of apoptosis protein (ML-IAP) or kidney inhibitor of apoptosis protein (KIAP), is a new member of the IAP family identified in melanocytoma $[2,3]$. High livin protein expression has been observed in multiple cancers, including breast cancer $[4,5]$, lung cancer [6], esophageal carcinoma [7], gastric cancer [8], renal cell cancer [9, 10], prostate cancer [11], and malignant pleural mesothelioma 
[12]. Little is currently known about the role of livin protein expression in the early diagnosis of tumors. It is thought that livin protein expression may be an early event in the occurrence of melanocytoma and HCC $[13,14]$; however, there is no consensus on the correlation between livin protein expression and the prognosis of different tumors. In China, it has been found that hepatitis and hepatic cirrhosis are major risk factors for HCC. The present study was, therefore, designed to investigate livin protein expression in three development stages, including hepatitis, hepatic cirrhosis, and HCC, so as to evaluate the role of livin protein expression in the early diagnosis and evaluation of the prognosis of HCC.

\section{Subjects and Methods}

2.1. Subjects. All subjects were sampled from the patients undergoing surgical treatment in the Department of Hepatobiliary Surgery, Tianjin Third Central Hospital, during the period from January 2003 to August 2006. Fifty HCC specimens were sampled during surgery, and diagnosis of HCC was confirmed by postsurgical pathological examination. In addition, the corresponding pericarcinoma liver tissues were resected. The 50 HCC patients included 42 males and 8 females, with a median age of 52 years, including 19 cases with high differentiation, 23 cases with moderate differentiation, and 8 cases with low differentiation. According to "Chinese Chronic Hepatitis B Treatment Guidelines" (2010) and "Primary Liver Cancer Diagnostic and Treatment Practices" (2011), among 50 HCC patients, there are 48 cases with hepatitis $\mathrm{B}$, one case with hepatitis $\mathrm{C}$, and one case with hepatitis B and hepatitis C coinfection; among the 49 patients with hepatitis $C$, there are $41 \mathrm{HBsAg}$ positive cases. 44 of these 50 HCC patients had cirrhosis, among which 42 cases with hepatitis $\mathrm{B}$, one case with hepatitis $\mathrm{C}$, and one case with hepatitis B and hepatitis C coinfection. Thirtytwo specimens of hepatitis/hepatic cirrhosis tissues and 29 specimens of normal liver tissues (sampled from perihepatic hemangioma tissues during the surgical treatment) served as controls. All patients were followed up from the day of surgery. In all 33 patients were dead by July 2011, and 17 patients remained alive. The median follow-up period was 27 months (range, 1-88 months). A total of 31 patients developed a relapse, and the median time to relapse was 11 months (range, 2-44 months). The blood plasma samples from 31 HCC patients were collected for the determination of livin protein expression, while the blood plasma samples from 7 patients with chronic hepatitis B, 7 cases with hepatic cirrhosis, and 8 healthy blood donors served as controls.

\subsection{Determination of Livin Protein Expression in Tissues and} Blood Plasma. Livin protein expression in HCC, pericarcinoma tissues, hepatitis/hepatic cirrhosis tissues, and normal liver tissues were determined using the two-step PV method of immunohistochemistry. All samples were fixed with $4 \%$ neutral formaldehyde solution; $4 \mu \mathrm{m}$ sections from formalinfixed, paraffin-embedded tissue blocks were deparaffinized, rehydrated, and treated with 3\% hydrogen peroxide for 15 minutes to inhibit endogenous peroxidase. Following heat-induced epitope retrieval in citrate buffer $(0.1 \mathrm{~mol} / \mathrm{L}$,
$\mathrm{pH}$ 6.0) on a pressure cooker for 2 minutes, the slides were incubated with rabbit anti-livin (1:50) (Catalog no. BA1743; Boster, Wuhan, China) overnight at $4^{\circ} \mathrm{C}$. Then the reaction was performed using the PV-9000 Polymer Detection System (Zhongshan Goldenbridge Biotechnology, Beijing, China). The staining was visualized using DAB solution and counterstained with hematoxylin. Immunohistochemical staining was performed according to the manufacturer's instructions.

The immunohistochemical stain results were identified by integrated scoring [15]. Four fields of view, each at $400 \times$ magnification, were randomly sampled from the upper, lower, left, right, and central part of the slice. The staining intensity of livin-positive cells in each field of view was observed, and the percentage of cells with this staining intensity in total hepatocyte or HCC cells in the nonnecrotic area was estimated. The immunohistochemical staining of livin protein was graded according to the percentage of livinpositive cells in the total hepatocyte: Grade 0 (negative), $\leq 5 \%$; Grade 1, 5\%-25\%; Grade 2, 25\%-50\%; and Grade 3, $\geq 50 \%$. The staining intensity of positive cells was classified into 4 grades: Grade 0 (negative), colorless; Grade 1, faint yellow; Grade 2, light brown; and Grade 3, puce. The integrated immunohistochemical staining results were scored by multiplying the percentage of positive cells by the staining intensity: score $0-1$, negative; score $2-3$, mildly positive; score $4-6$, moderately positive; score $7-9$, strongly positive.

Livin protein expression was detected in the blood plasma of HCC patients, subjects with hepatic cirrhosis and hepatitis, and healthy blood donors, using enzyme-linked immunosorbent assay (ELISA). The reagent kit was supplied by USCNK (E96518Hu, USCN Life Science, Wuhan, China).

The ELISA results were identified as follows. A standard curve was plotted based on the concentration of the standard sample (horizontal coordinate) and the optical densities (OD) of the standard sample (longitudinal coordinate). The concentration corresponding to the $\mathrm{OD}$ value of the test sample was estimated based on the standard curve. The actual concentration of the test sample was calculated by multiplying this concentration by the dilution ratio.

\subsection{Statistical Analysis. All statistical analyses were per-} formed using the statistical software SPSS version 13.0 (SPSS Inc., Chicago, IL, USA). Between-groups comparison was done with the rank-sum test. The correlation of livin protein expression between tissues and blood plasma was assessed using Spearman's rank correlation analysis, and the association of livin protein expression in tissues and blood plasma with the clinicopathological characteristics was estimated with Fisher's exact test. A Kaplan-Meier curve was plotted to assess the correlation between livin protein expression and the prognosis of HCC. A $P$ value $<0.05$ was considered statistically significant.

\section{Results}

3.1. Livin Protein Expression in Different Tissues. Livin protein was mainly expressed in cytoplasm, with positive expression rates of $54.00 \%(27 / 50)$ and $44.00 \%(22 / 50)$ in the 


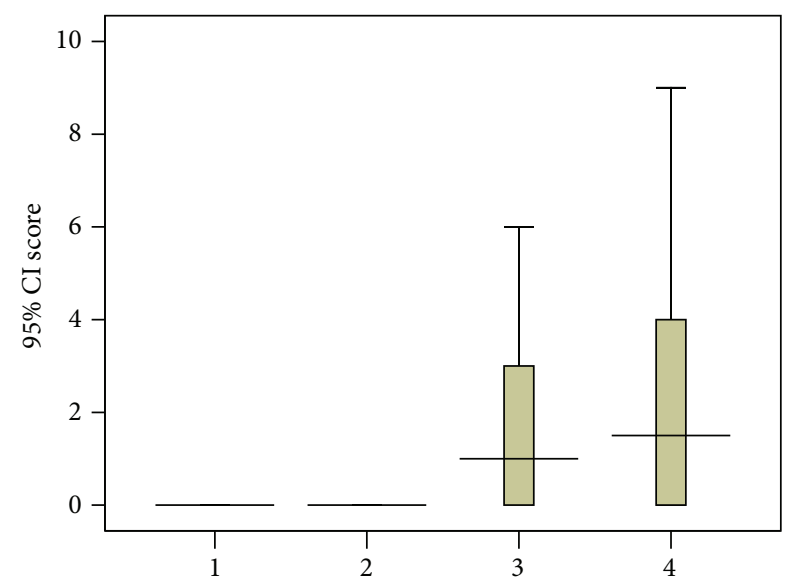

FIGURE 1: Immunohistochemical staining determines livin protein expression in tissues. 1: normal liver tissues; 2: hepatitis/hepatic cirrhosis tissues; 3 : pericarcinoma tissues; 4: hepatocellular carcinoma tissues.

HCC tissues and pericarcinoma tissues, respectively, and no significant difference was observed $(P>0.05)$. The positive livin protein expression was mainly characterized by mildly and moderately positive expression, being $44.44 \%$ and $51.85 \%$ in the HCC tissues and $50.00 \%$ and $50.00 \%$ in the pericarcinoma tissues, respectively. Among the 50 samples of pericarcinoma tissues, there are 30 cases with liver cell dysplasia (LCD) complications, of which 15 cases (50\%) are livin protein positive. Among the other 20 cases without LCD, livin protein of 7 cases $(35 \%)$ expresses positive. There are no significant differences $(P=0.225)$. Livin protein was positive in only $3.44 \%(1 / 29)$ of normal liver tissues and in only $3.13 \%(1 / 32)$ of the hepatitis/hepatic cirrhosis tissues, and no significant difference was observed $(P>0.05)$. The positive expression rate of livin protein was significantly higher in the HCC tissues than that in the normal liver tissues and in the hepatitis/hepatic cirrhosis tissues $(P<0.001$ and $P=0.001$, resp.) (Table 1, Figures 1 and 2).

3.2. Livin Protein Expression in Blood Plasma. The median expression of livin protein was 29.348, 27.774, 29.930, 29.376, and $2.348 \mathrm{ng} / \mathrm{L}$ in the blood plasma of the patients with HCC before and after surgery, patients with hepatic cirrhosis, patients with hepatitis, and healthy blood donors, respectively. Livin protein expression was significantly higher in the blood plasma of HCC patients before and after surgery, patients with hepatic cirrhosis, and patients with hepatitis than that in the blood plasma of the healthy blood donors $(P<0.001, P=0.003,0.014$, and 0.009 , resp.), while no significant differences were found in livin protein expression in blood plasma from HCC patients before and after surgery, patients with hepatic cirrhosis, and patients with hepatitis $(P>0.05)$ (Figure 3).

3.3. Correlation of Livin Protein Expression between Tissues and Blood Plasma. Livin protein expression was significantly higher in the HCC tissues than that in the hepatitis/hepatic cirrhosis tissues and normal liver tissues, while there were no significant differences observed between livin protein expression in the blood plasma from the HCC patients, patients with hepatic cirrhosis, and patients with hepatitis. However, Spearman's rank correlation analysis on 31 corresponding patents revealed no correlation between livin protein expression in tissues and in blood plasma $(P=0.256)$.

3.4. Association of Livin Protein Expression in HCC with the Clinicopathological Characteristics of HCC. Livin protein expression in the tissues and blood plasma of HCC was found not to be associated with the clinicopathological characteristics of HCC, including patient's age, tumor diameter, growth pattern, degree of differentiation, presence of metastasis, or recurrence (Table 2). The HCC patients with positive livin protein expression in HCC tissues had a significantly higher survival rate relative to those with negative livin protein expression $(P=0.025)$, while livin protein expression in the blood plasma of the HCC patients had no effect on the survival rate of HCC patients (Figure 4).

\section{Discussion}

Livin is a member of the IAP family, characterized by the presence of an $\mathrm{N}$-terminal, conserved, single BIR domain and a C-terminal RING-type zinc finger domain, which fulfills the roles of combination and intracellular localization [16]. Livin protein combines directly with caspase, and it enables other IAP family members to combine with caspase through the combination with Smac/DIABLO protein, thereby inhibiting the apoptosis of normal cells $[17,18]$. Thus, livin protein is highly expressed in multiple tumors, while livin protein expression is absent in normal tissues.

The present study detected significantly higher expression of livin protein in the HCC and pericarcinoma tissues than in the hepatitis/hepatic cirrhosis tissues; however, livin protein expression in the HCC tissues was not significantly different from that in the pericarcinoma tissues. This might because pericarcinoma tissues and hepatic cirrhosis tissues are different at protein and gene levels. The expression of livin protein may occur in the early stage of HCC. Livin protein expression has been shown to be an early-stage event during the development of HCC. HCC with earlier TNM stages is found to have a higher positive expression rate of the livin protein [13]. It has been shown that livin protein expression in melanoma patients is associated with the tumor size, and the melanoma with a smaller diameter expresses a higher level of livin protein (tumor diameter $>4 \mathrm{~mm}$ versus tumor diameter $<2 \mathrm{~mm}, P=0.09$ ), suggesting that early-stage melanoma expresses a high level of livin protein [14]. Our findings suggested that HCC with a smaller diameter tends to express higher levels of livin protein; however, no significant difference was detected, which may be attributable to the small sample size. Therefore, livin protein expression in the pericarcinoma tissues may be an early-stage event during the occurrence of HCC.

The positive expression of livin protein and the livin gene have been reported to correlate with cancer prognosis; 


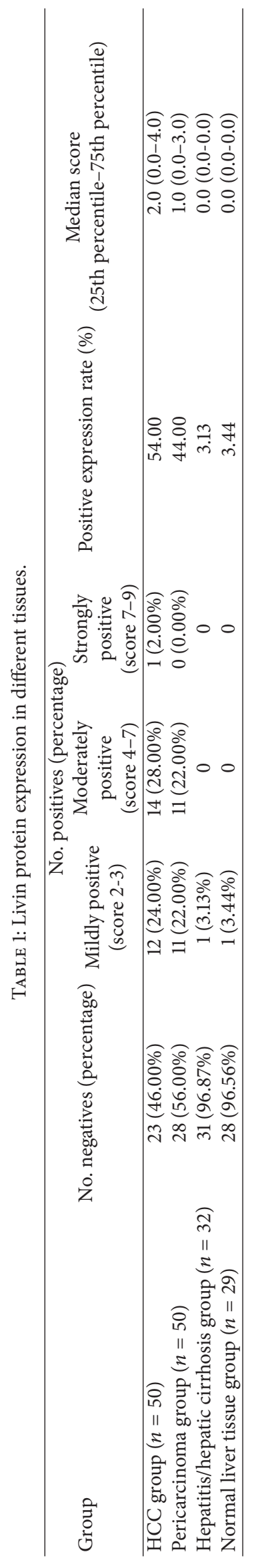




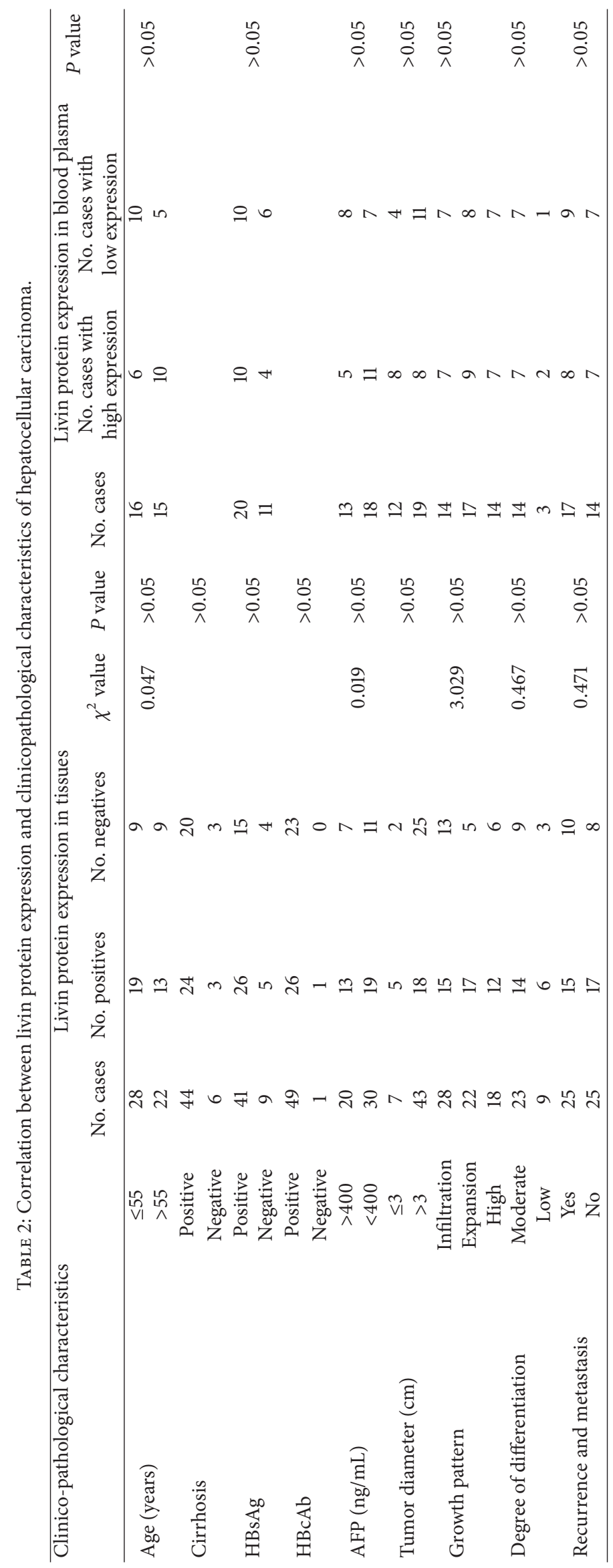




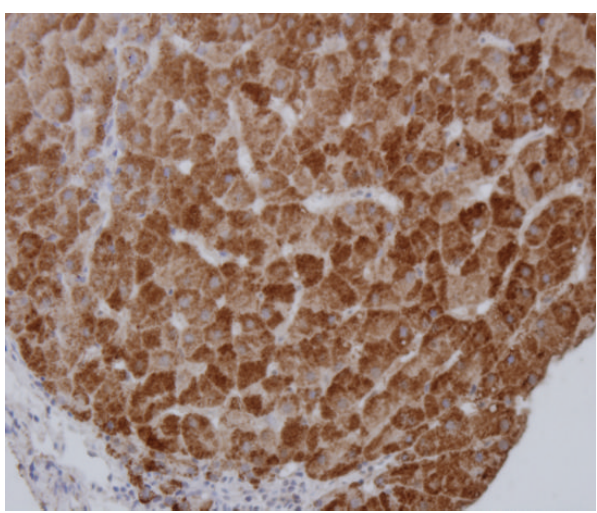

(a)

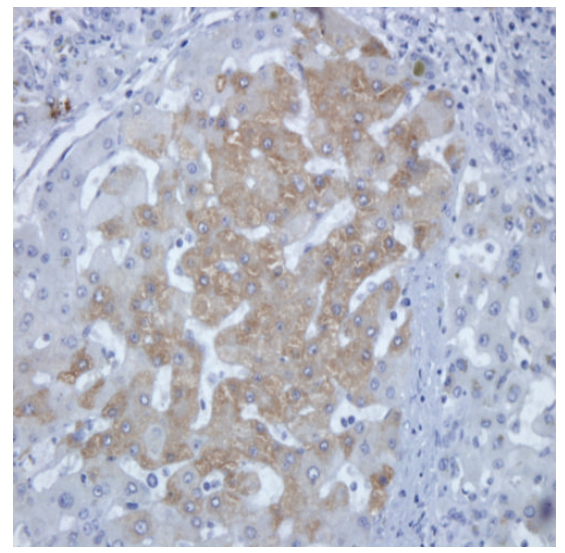

(d)

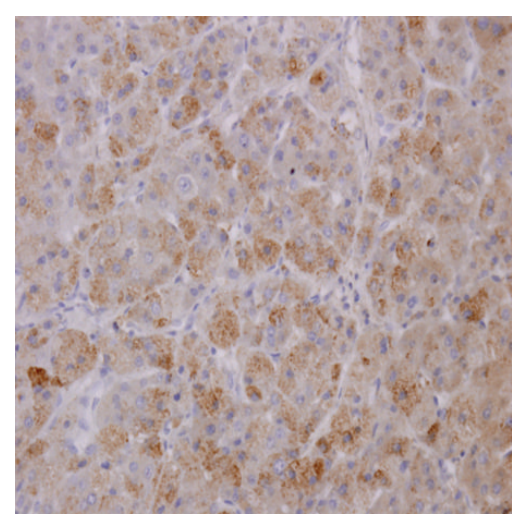

(b)

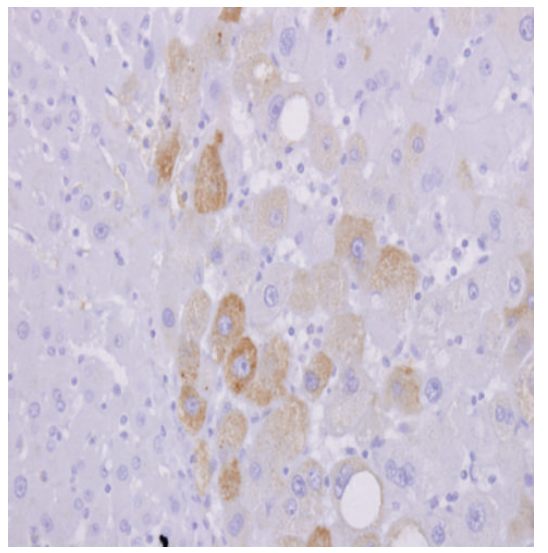

(e)

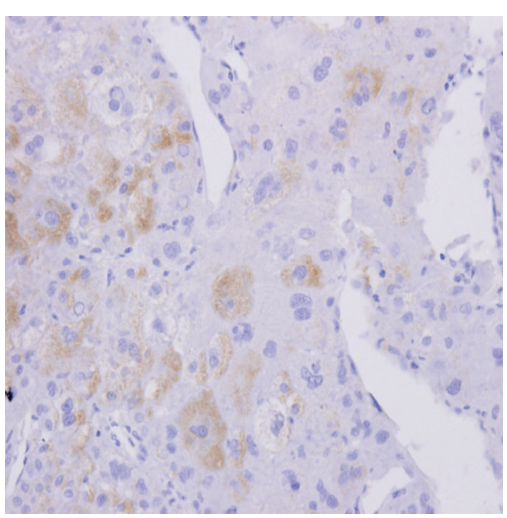

(c)

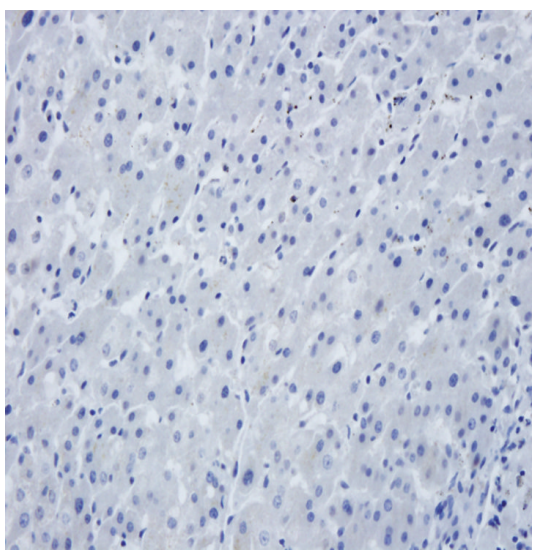

(f)

Figure 2: (a), (b), and (c) strongly, moderately, and mildly positive expression of livin in HCC tissues ( $\times 400)$; (d) and (e) moderately and mildly positive expression of livin in pericarcinoma tissues $(\times 400)$; (f) negative livin protein expression in normal liver $(\times 400)$.

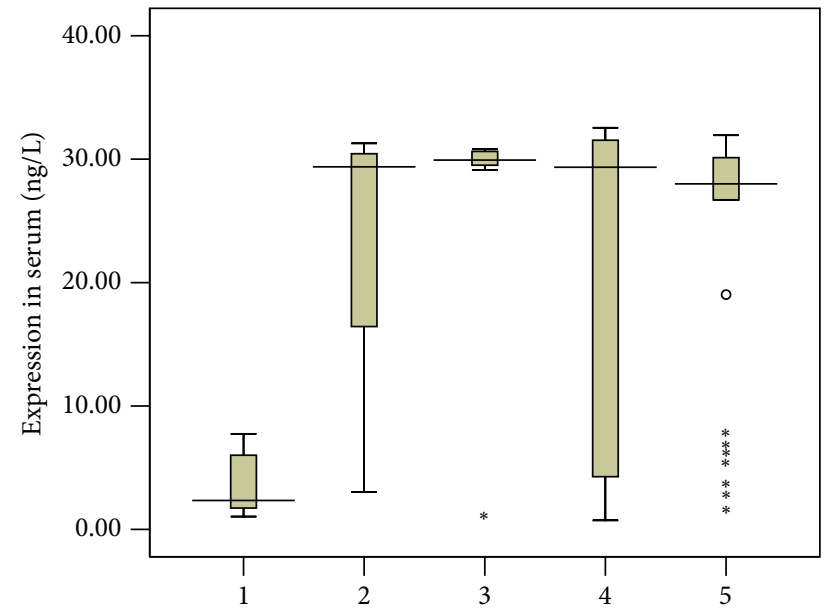

FIGURE 3: ELISA determines livin protein expression in blood plasma. 1: healthy blood donors; 2: hepatitis patients; 3: hepatic cirrhosis patients; 4: hepatocellular carcinoma patients before surgery; 5: hepatocellular carcinoma patients after surgery.

however, the correlation between livin protein expression and prognosis in different cancers remains controversial.
High nuclear livin protein expression is found to predict satisfactory prognosis of renal cell carcinoma [19], and children with acute lymphoblastic leukemia positive for livin protein are reported to have a satisfactory prognosis [20]. However, it appears that high expression of the livin gene predicts poor prognosis of breast cancer [21], and high livin protein expression is reported to be associated with earlystage relapse of breast cancer and the lymph node metastasis of ampullary carcinoma [22,23]. In addition, livin expression is found not to be associated with the prognosis of HCC [24], and the expression of the livin gene is reported not to be related to the survival period of patients with nonsmall-cell lung cancer [6]. The present study found that HCC patients with positive livin protein expression in HCC tissues had a significantly higher survival rate than those with negative expression. In addition, patients with melanoma complicated by chronic diseases who express moderate or low levels of livin protein are found to have a higher survival rate relative to those without livin protein expression [14]. In the current study, over $80 \%$ of the HCC patients suffered from hepatitis B or C, most of whom had already developed hepatic cirrhosis, and moderately and mildly positive expression of livin expression was detected in most patients, which is in agreement with the results from the study by Lazar et 


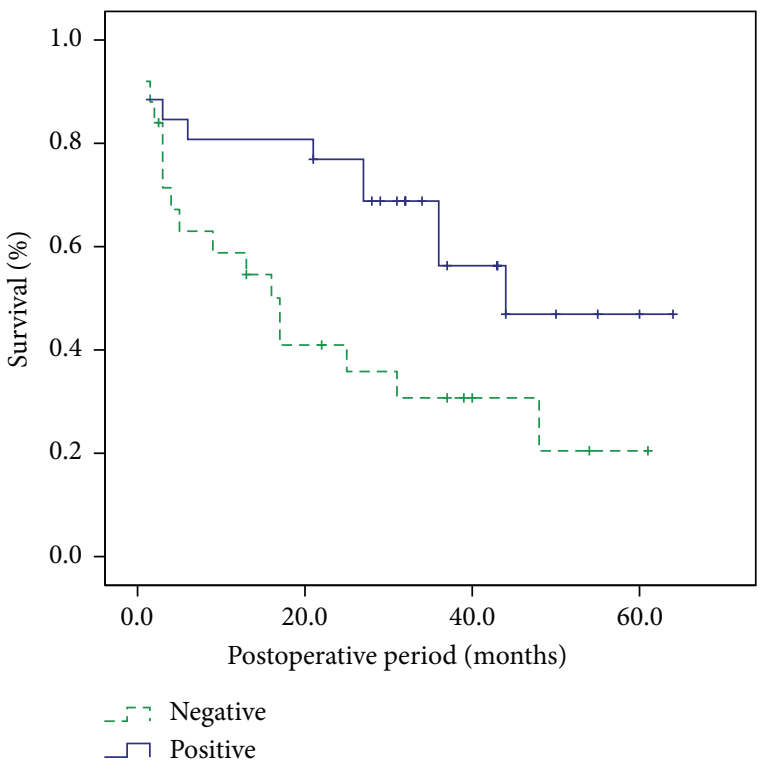

(a)

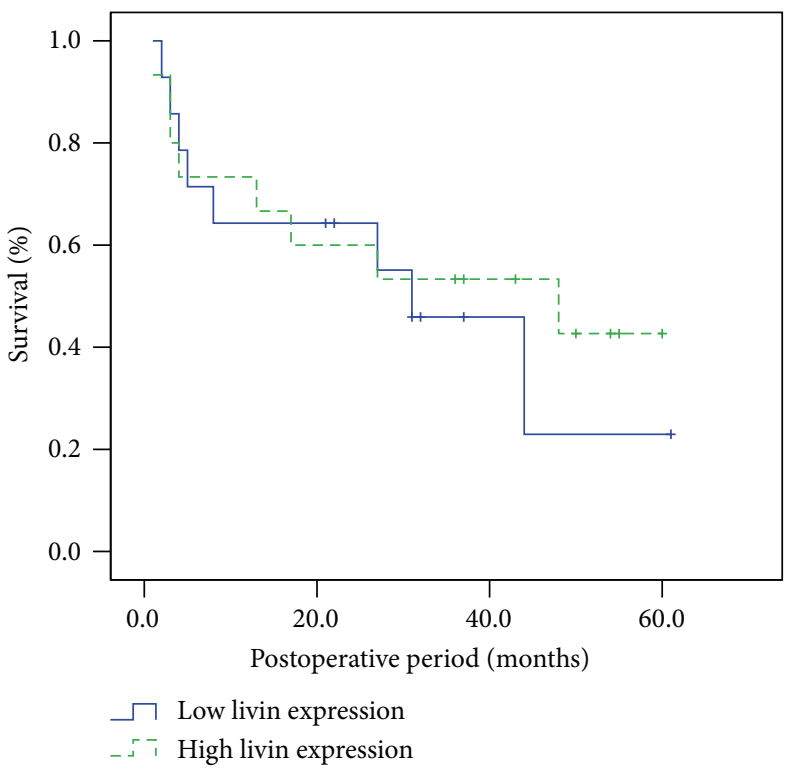

(b)

Figure 4: (a) Kaplan-Meier survival curve for livin protein expression in tissues; (b) Kaplan-Meier survival curve for livin protein expression in blood plasma.

al. [14]. This finding may be associated with the activation of cytotoxic T cells (CTLs) by moderate or low levels of livin protein, which triggers immune responses and then increases the patients' survival rate [25]. It seems that livin protein can induce the activation of CTLs, which infiltrate into the microenvironments and blood circulation of tumors, thereby directly killing tumor cells. Therefore, livin protein expression in HCC tissues may be an effective indicator for assessing the prognosis of HCC patients, and it may become a novel target for immunotherapy of HCC.

To our knowledge, there has been no previous report on livin protein expression in the blood plasma from the patients with hepatitis and hepatic cirrhosis. Our finding showed that livin protein expression in the blood plasma from the patients with hepatitis and hepatic cirrhosis was significantly higher than that in the blood plasma from healthy blood donors; however, livin protein expression in the blood plasma from the patients with hepatitis and hepatic cirrhosis was not significantly different from that in the blood plasma from the HCC patients. In addition, the low livin protein expression in the hepatitis/hepatic cirrhosis tissues was found to be inconsistent with the high expression in the blood plasma from the patients with hepatitis and hepatic cirrhosis, suggesting that other tissues may express livin protein, which may then enter the blood. The underlying causes require further studies with a larger sample size. The high expression of livin protein in the blood plasma from patients with hepatitis and hepatic cirrhosis suggests that livin protein may not be suitable for the serodiagnosis of early-stage HCC.

\section{Acknowledgments}

This study was supported by Grants from the Research Project on Basic Science of Tianjin Healthy Bureau (07KY14) and the Key Research Project of Tianjin Healthy Bureau (11KG112).

\section{References}

[1] C. D. Witjes, S. M. van Aalten, E. W. Steyerberg et al., "Recently introduced biomarkers for screening of hepatocellular carcinoma: a systematic review and meta-analysis," Hepatology International, vol. 7, no. 1, pp. 59-64, 2013.

[2] D. Vucic, H. R. Stennicke, M. T. Pisabarro, G. S. Salvesen, and V. M. Dixit, "ML-IAP, a novel inhibitor of apoptosis that is preferentially expressed in human melanomas," Current Biology, vol. 10, no. 21, pp. 1359-1366, 2000.

[3] G. M. Kasof and B. C. Gomes, "Livin, a novel inhibitor of apoptosis protein family member," The Journal of Biological Chemistry, vol. 276, no. 5, pp. 3238-3246, 2001.

[4] X. Chen, T. Wang, D. Yang et al., "Expression of the IAP protein family acts cooperatively to predict prognosis in human bladder cancer patients," Oncology Letters, vol. 5, pp. 1278-1284, 2013.

[5] F. Li, X. Yin, X. Luo et al., "Livin promotes progression of breast cancer through induction of epithelial-mesenchymal transition and activation of AKT signaling," Cell Signal, vol. 25, no. 6, pp. 1413-1422, 2013.

[6] C. H. Dai, J. Li, S. B. Shi, L. C. Yu, L. P. Ge, and P. Chen, "Survivin and Smac gene expressions but not livin are predictors of prognosis in non-small cell lung cancer patients treated with adjuvant chemotherapy following surgery," Japanese Journal of Clinical Oncology, vol. 40, no. 4, Article ID hyp165, pp. 327-335, 2010.

[7] L. Chen, G. S. Ren, F. Li, and S.-Q. Sun, "Expression of Livin and vascular endothelial growth factor in different clinical stages of human esophageal carcinoma," World Journal of Gastroenterology, vol. 14, no. 37, pp. 5749-5754, 2008. 
[8] Y. Z. Liang, T. Y. Fang, H. G. Xu et al., "Expression of CD44v6 and Livin in gastric cancer tissue," Chinese Medical Journal, vol. 125, no. 17, pp. 3161-3165, 2012.

[9] N. Wagener, I. Crnković-Mertens, C. Vetter et al., "Expression of inhibitor of apoptosis protein Livin in renal cell carcinoma and non-tumorous adult kidney," The British Journal of Cancer, vol. 97, no. 9, pp. 1271-1276, 2007.

[10] T. Cheng, J. G. Zhang, Y. H. Cheng et al., "Relationship between PTEN and Livin expression and malignancy of renal cell carcinomas," Asian Pacific Journal of Cancer Prevention, vol. 13, no. 6, pp. 2681-2685, 2012.

[11] L. Ye, S. Li, D. Ye et al., "Livin expression may be regulated by miR-198 in human prostate cancer cell lines," European Journal of Cancer, vol. 49, no. 3, pp. 734-740, 2013.

[12] G. J. Gordon, M. Mani, L. Mukhopadhyay et al., "Expression patterns of inhibitor of apoptosis proteins in malignant pleuralmesothelioma," The Journal of Pathology, vol. 211, pp. 447454, 2007.

[13] H. Hu, C. J. Wang, L. Gong et al., "Expression and significance of apoptosis inhibitor livin in hepatocellular carcinoma," Chinese Journal of Hepatobiliary Surgery, vol. 13, no. 5, p. 348, 2007.

[14] I. Lazar, R. Perlman, M. Lotem, T. Peretz, D. Ben-Yehuda, and L. Kadouri, "The clinical effect of the inhibitor of apopotosis protein livin in melanoma," Oncology, vol. 82, no. 4, pp. 197-204, 2012.

[15] Y. X. Zeng, Ed., Oncology, People’s Medical Publishing House, Beijing, China, 2nd edition, 2003.

[16] R. Hegde, S. M. Srinivasula, Z. Zhang et al., "Identification of $\mathrm{Omi} / \mathrm{HtrA} 2$ as a mitochondrial apoptotic serine protease that disrupts inhibitor of apoptosis protein-caspase interaction," The Journal of Biological Chemistry, vol. 277, no. 1, pp. 432-438, 2002.

[17] L. Ma, Y. Huang, Z. Song et al., "Livin promotes Smac/DIABLO degradation by ubiquitin-proteasome pathway," Cell Death and Differentiation, vol. 13, no. 12, pp. 2079-2088, 2006.

[18] D. Vucic, M. C. Franklin, H. J. A. Wallweber et al., "Engineering ML-IAP to produce an extraordinarily potent caspase 9 inhibitor: implications for Smac-dependent anti-apoptotic activity of ML-IAP," Biochemical Journal, vol. 385, no. 1, pp. 1120, 2005.

[19] A. Haferkamp, J. Bedke, C. Vetter et al., "High nuclear Livin expression is a favourable prognostic indicator in renal cell carcinoma," The British Journal of Urology International, vol. 102, no. 11, pp. 1700-1706, 2008.

[20] J. Choi, K. H. Yu, W. S. Ki et al., "Expression of Livin, an antiapoptotic protein, is an independent favorable prognostic factor in childhood acute lymphoblastic leukemia," Blood, vol. 109, no. 2, pp. 471-477, 2007.

[21] P. Gazzaniga, A. Gradilone, L. Giuliani et al., "Expression and prognostic significance of LIVIN, SURVIVIN and other apoptosis-related genes in the progression of superficial bladder cancer," Annals of Oncology, vol. 14, no. 1, pp. 85-90, 2003.

[22] R. C. Xi, Y. R. Sheng, W. H. Chen et al., "Expression of survivin and livin predicts early recurrence in non-muscle invasive bladder cancer," Journal of Surgical Oncology, vol. 107, no. 5, pp. 550-554, 2013.

[23] D. Xue, K. Zuo, X. Li et al., "Expression and prognostic significance of Livin, Caspase-3, and Ki-67 in the progression of human Ampullary Carcinoma," Applied Immunohistochemistry \& Molecular Morphology, 2013.

[24] C. Augello, L. Caruso, M. Maggioni et al., "Inhibitors of apoptosis proteins (IAPs) expression and their prognostic significance in hepatocellular carcinoma," BMC Cancer, vol. 9, article 125, 2009.

[25] M. H. Andersen, S. Reker, J. C. Becker, and P. T. Straten, "The Melanoma inhibitor of apoptosis protein: a target for spontaneous cytotoxic T cell responses," Journal of Investigative Dermatology, vol. 122, no. 2, pp. 392-399, 2004. 


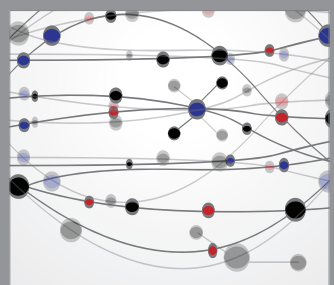

The Scientific World Journal
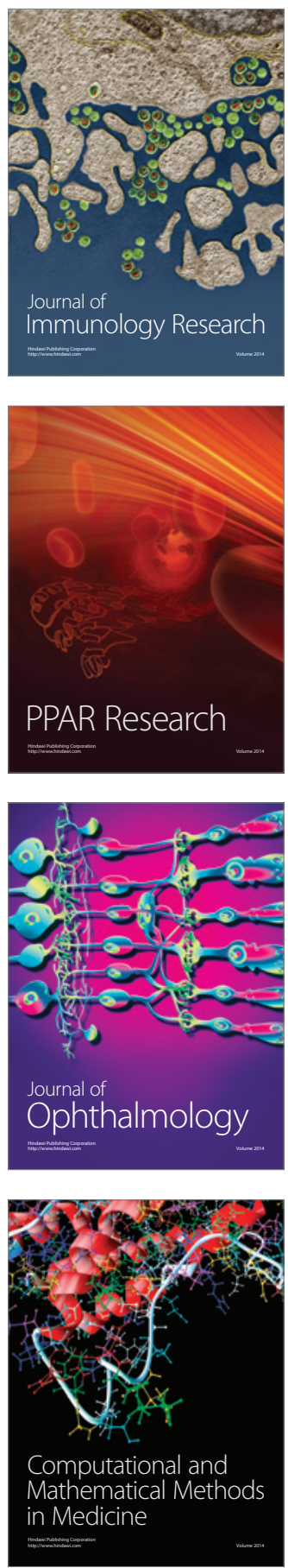

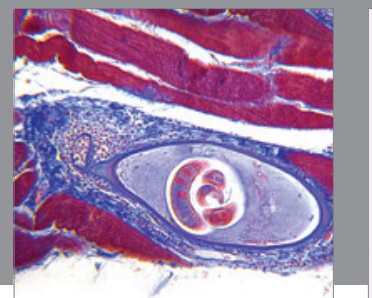

Gastroenterology

Research and Practice
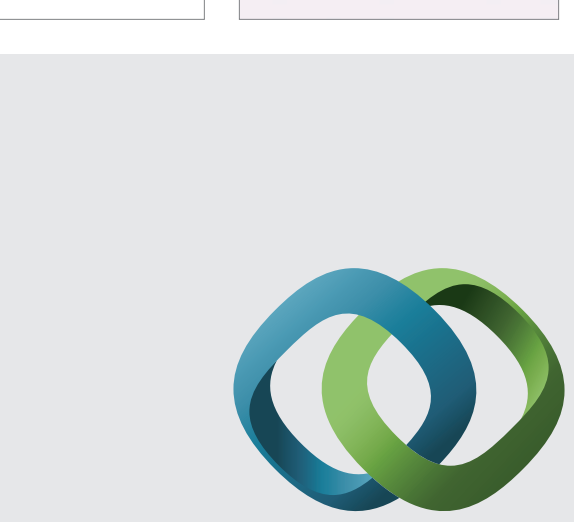

\section{Hindawi}

Submit your manuscripts at

http://www.hindawi.com
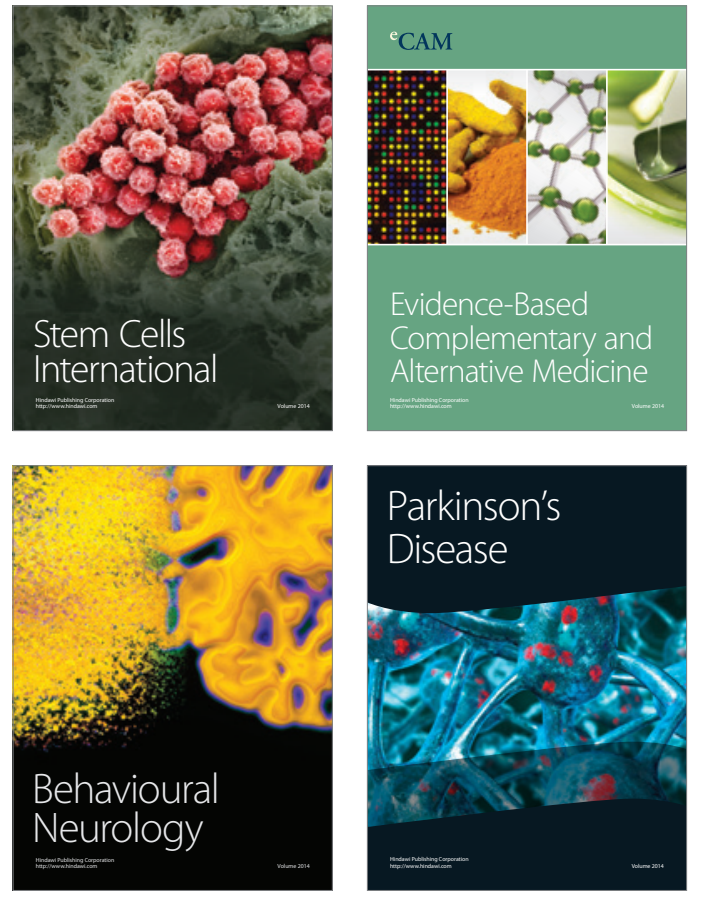
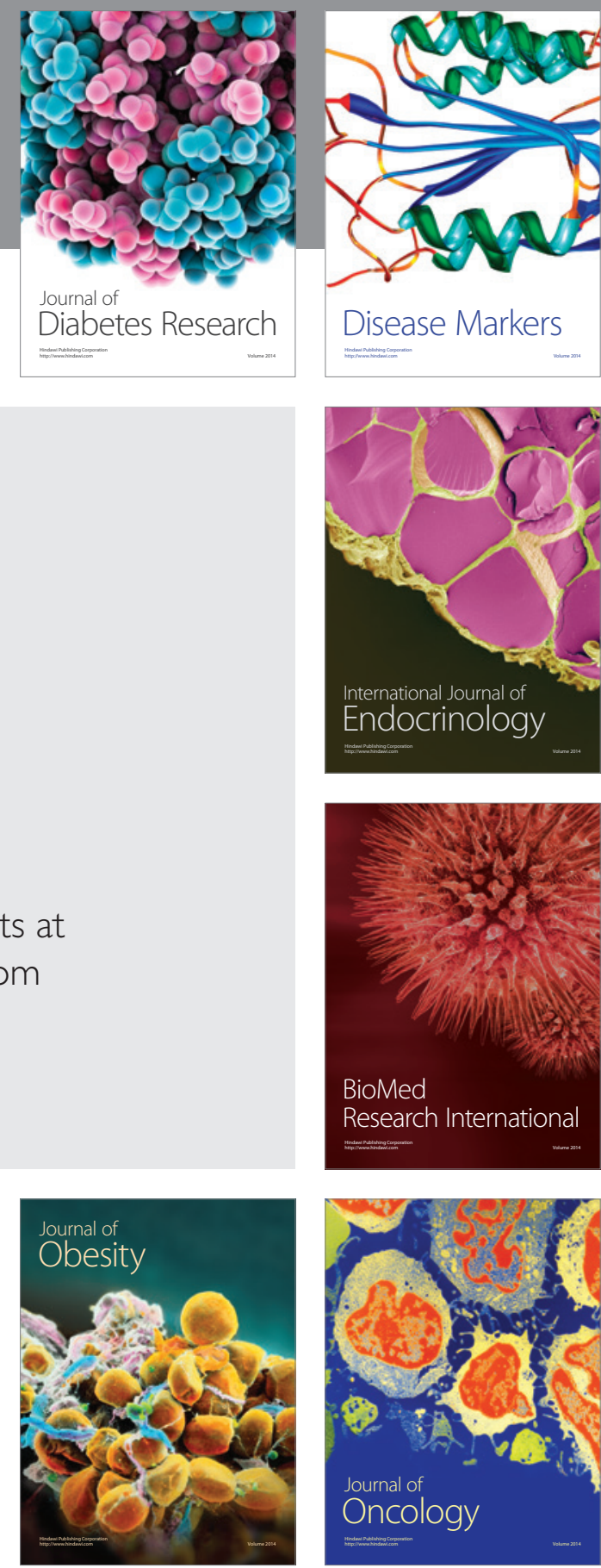

Disease Markers
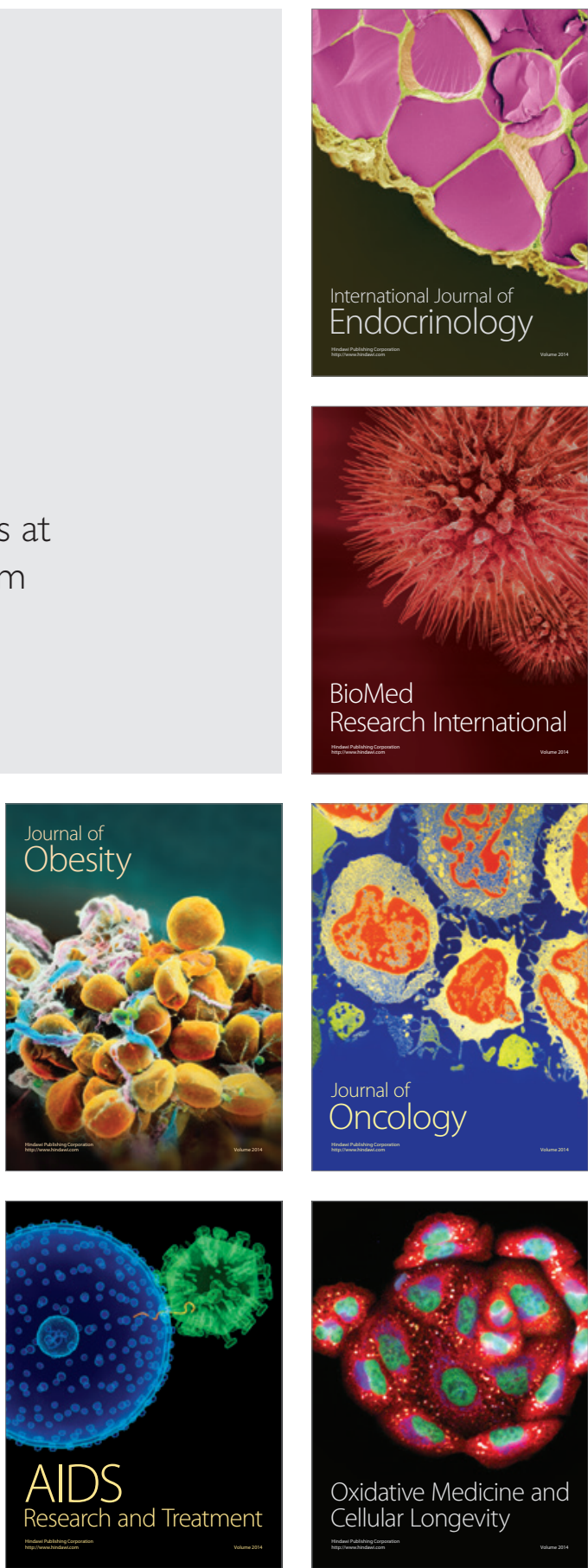